\title{
Parkinson's Disease and Exposure to Rural Environmental Factors: A Population Based Case-Control Study
}

\author{
Karen M. Semchuk, Edgar J. Love and Robert G. Lee
}

\begin{abstract}
To determine whether a history of exposure to rural environmental factors leads to an increased likelihood of developing idiopathic Parkinson's disease, we conducted a case-control study of 130 cases and 260 randomly selected community controls (matched with the cases by sex and age \pm 2.5 years at a ratio of 2 controls: 1 case) in the city of Calgary. The data were collected by personal interviews and were analyzed using conditional logistic regression for matched sets. The ages of the cases ranged from 36.5 to 90.7 years (mean $=68.5 \pm 11.3$ years). The mean age at diagnosis was $61.1 \pm 12.4$ years. The mean duration of disease was $7.8 \pm 0.6$ years. Eleven $(9.1 \%)$ cases were diagnosed before age 40 . In this sample from the Province of Alberta, Canada, no significant increase in risk for Parkinson's disease was associated with a history of rural living, farm living, or well water drinking in early childhood or at any time during the first 45 years of life.

RÉSUMÉ: Maladie de Parkinson et exposition à des facteurs environnementaux ruraux: une étude de population cas-témoin. Nous avons procédé à une étude cas-témoin sur 130 cas et 260 contrôles sélectionnés de façon aléatoire dans la communauté (appariés aux cas pour le sexe et l'âge \pm 2.5 ans dans la proportion de 2 contrôles pour 1 cas) dans la ville de Calgary, afin de déterminer si une histoire d'exposition à des facteurs environnementaux ruraux entraîne une probabilité augmentée de développer une maladie de Parkinson idiopathique. Les données ont été recueillies lors d'entrevues personnelles et ont été analysées au moyen de la régression logistique conditionnelle pour des groupes appariés. L'âge des cas variait de 36.5 à 90.7 ans (moyenne $=68.5 \pm 11.3$ ans). L'âge moyen au diagnostic était de $61.1 \pm 12.4$ ans. La durée moyenne de la maladie était de $7.8 \pm 0.6$ ans. Onze cas $(9.1 \%)$ avaient été diagnostiqués avant l'âge de 40 ans. Dans cet échantillon résidant dans la province d'Alberta, Canada, aucune augmentation signifivative du risque de développer la maladie de Parkinson n'était associé à une histoire de résidence rurale, de résidence sur une ferme, ou d'absorption d'eau de puits dans la petite enfance ou à tout autre moment pendant les 45 premières années de vie.
\end{abstract}

Can. J. Neurol. Sci. 1991; 18:279-286

Parkinson's disease (PD) is one of the most common adult neurological disorders. ${ }^{1,2}$ Despite major advances in the understanding of its pathogenesis and in its treatment, and despite intensive research over the past two decades, the etiology of PD is still unknown. It has been postulated, but in no case confirmed, that Parkinson's disease is: inherited; 3 -15 linked to known viruses; $6,16-22$ associated with other diseases and conditions including: arteriosclerosis, ${ }^{23-25}$ diabetes, ${ }^{23-25}$ cancer, $23-25$ coronary heart disease, ${ }^{23-26}$ hypotension, $6,22,25,27,28$ peptic ulcer, ${ }^{23,24}$ pulmonary tuberculosis, ${ }^{25}$ stroke, $6,23,24$ thyroid disease, 23,24 and other diseases and conditions; $6,23-25,28,29$ a neurofilament disorder; ${ }^{30-33}$ the result of defective DNA repair mechanisms; ${ }^{34}$ associated with: certain personality traits, ${ }^{10,35,36}$ dietary factors, ${ }^{37}$ familial essential tremor, 4,6,9,38-42 ionizing radiation, 22 and toxic and/or environmental factors. 10,23,29,43-61 More recently, a multifactorial etiology has been hypothesized, that is PD is the result of a combined effect of genetic and environmental factors acting on a background of aging. 22.44.49.52. 53,62-64 There has been a recent focus on urban-rural differences, on well water drinking in childhood, and on pesticide use. $49,50,52,53,60,61.65-72$

To date, there have been no cohort studies of PD, and no environmental factors have been consistently identified in casecontrol studies. Previous case-control studies have attempted to investigate the relationships between the risk for developing PD, rural living and well water drinking, $67-71$ but they have yielded

From the Departments of Community Health Sciences (K.M.S., E.J.L.) and Clinical Neurosciences (R.G.L.), Faculty of Medicine, The University of Calgary, Calgary

Received December 13, 1990. Accepted January 31, 1991

Reprint requests to: Karen M. Semchuk, Ph.D., Centre for Agricultural Medicine, University of Saskatchewan, Royal University Hospital, Saskatoon, Saskatchewan, Canada S7N 0X0 
inconsistent results (Table 1). On review, the results reported in this paper conflict with the results of the previous case-control studies. However, unlike this study, none of the previous casecontrol studies were population based.

This paper presents the results of a population based casecontrol study of PD which was conducted in the city of Calgary to investigate whether or not exposure to environmental factors associated with rural living leads to an increased likelihood of developing idiopathic PD. This study is the largest environmental case-control study of PD, reported to date, and it is the first one which was population based. The study tested the following hypotheses: a) individuals with a history of rural living, particularly in areas specializing in agriculture, have an increased risk of developing Parkinson's disease; b) well water drinking, especially in early childhood, is associated with an increased risk of developing Parkinson's disease.

\section{Methods}

Prior to starting this study, a case register of 232 Calgary residents with neurologist-confirmed idiopathic PD was developed as follows. With the assistance of the Medical Records Department at each of the five general hospitals, a computer listing was made of all patients with a primary or additional diagnosis of PD who were discharged from hospital between January 1, 1984 and December 31, 1987. With the aid of the computerized Longterm Care Information System for Calgary, which maintains a current listing of all Calgary longterm care facility residents, along with their diagnoses, and with the cooperation of auxiliary hospitals, which allowed the study personnel to review their residents' charts, a computer listing was made of current longterm care facility residents with a diagnosis of PD. The Movement Disorder Clinic (The University of Calgary Medical Clinic) and the 16 neurologists practicing in Calgary assisted the study personnel in compiling a list of their patients with PD. The Parkinson's Society of Southern Alberta provided a roster of its current Calgary membership.

The data from all of these sources were merged into one master file. For every patient identified from these sources, a review of the medical chart was done in order to locate documentation by a qualified consulting neurologist confirming the diagnosis of idiopathic PD. For each name gathered through the Parkinson's Society, the attending neurologist was contacted in order to confirm the diagnosis. Thus, for each case, the diagnosis of idiopathic PD was made by a qualified consultant neurologist. In general, this diagnosis was made in the presence of two or more of the four cardinal signs of PD: resting tremor, muscle rigidity, bradykinesia, and disturbances of posture and equilibrium. We excluded from the register those cases whose parkinsonian symptoms were drug-induced or could be attributed to: essential tremor, a Parkinson syndrome (i.e., progressive supranuclear palsy, normal pressure hydrocephalus, multiinfarct dementia, olivopontocerebellar degeneration, and ShyDrager syndrome), encephalitis, Alzheimer's disease, head trauma, tumor, or to chemical intoxication. The names of all non-Calgary residents and of all individuals in whom the diagnosis of PD was not confirmed by a neurologist were removed from the master file, leaving a case register of Calgary residents in whom the diagnosis of idiopathic PD had been confirmed by a qualified neurologist.

For each case included in the case register, the attending neurologist was contacted in order to determine the case's eligibility for the study. Eighty-five ineligible cases (37 deceased, 27 demented, 13 non-resident, and 5 in whom the diagnosis of PD was not confirmed by their current attending neurologists) were excluded from the study. Surrogates of deceased and demented cases were not used due to the questionable accuracy of information obtained from surrogates about factors such as well water consumption during early childhood. The initial contact with each eligible case about the study was made through the case's attending physician.

For each case, two community controls, who were individually matched with the index case by sex and age \pm 2.5 years, were randomly selected from the Calgary general population using random-digit-dialing (RDD) sampling procedures. ${ }^{73-76}$ The sampling frame for the community controls included all Calgary residential telephone numbers including those unlisted and unpublished. Approximately 95 percent of all Calgary households have a telephone.(1) The RDD procedures were as follows. Using a list of operating telephone exchanges in Calgary, and the Minitab ${ }^{77}$ statistical software program, a random sample of Calgary telephone numbers was generated. Each generated number was called up to 10 times (at different times of the day and week) in order to determine if the number was a

\footnotetext{
(1)Estimate provided by the City of Calgary Corporate Resources Department.
}

Table 1: Case-Control Studies of Parkinson's Disease and Rural Environmental Factors

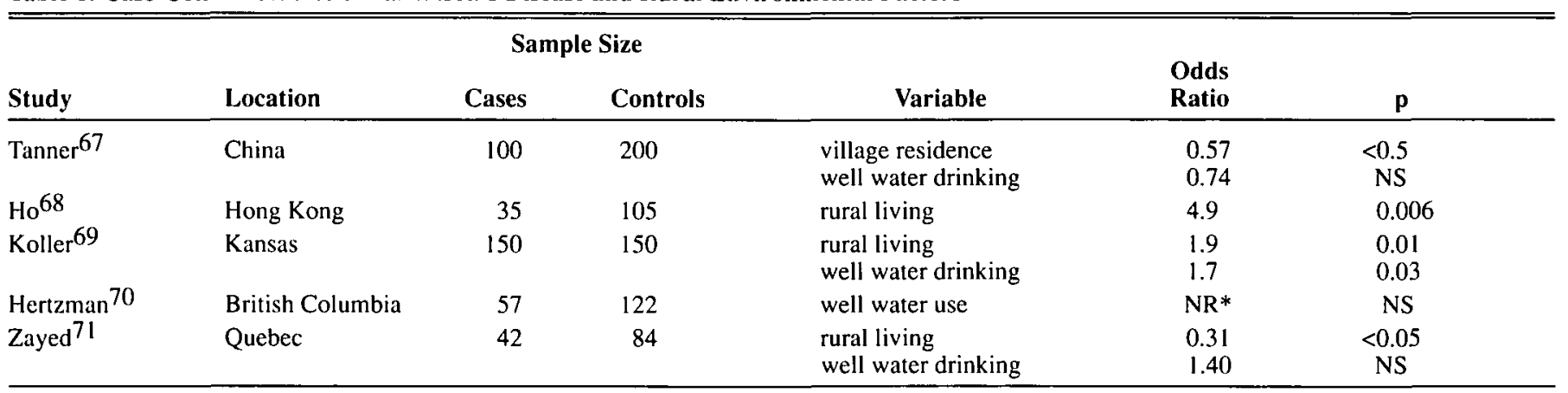

*Not reported 
residential number and, if so, to obtain a listing, by age and sex, of all eligible household residents. Residents who were unable to understand and answer the research questions and those with parkinsonism or other neurologic conditions were excluded as potential controls. Only one potential control was selected from each household, using a table of random number when two or more residents were eligible.

To permit analysis of any bias due to institutionalization, for each of 23 cases who resided in longterm care facilities, one additional matched control was selected from the resident censuses of 6 longterm care facilities in which the institutionalized cases resided.

Once identified, all eligible cases and controls were provided with an introductory letter inviting their participation in the study. The letters to the cases were signed by the patients' attending physicians. The letters to the controls were signed by the investigators. Those cases and controls who were willing to participate were interviewed by trained experienced interviewers, To minimize recall bias pains were taken to ensure consistency, between the cases and the controls, in the procedures used to obtain information about exposure. A list of dates of significant historical events was used to assist the respondents in recalling the year of exposure. To assist the respondents in recalling the month, the interviewers were trained to prompt the respondent for the season, first. To minimize interviewer and respondent bias the underlying hypotheses of the study were not revealed to either the interviewers or the respondents. A number of consistency checks were built into the interview to validate responses, for example, by asking the same question in a number of different ways.

Each respondent was asked for a complete residential history, including the location and dates of residence for each place resided, for the first 45 years of life, and for various demographic data: age, sex, date of birth, marital status, educational level, annual family income, ethnic background, and household size. The cases were also asked to recall the age at symptom onset and the age at diagnosis. For each residence named, the respondent was asked about the source of drinking water (i.e., well, central water supply, river, lake, etc.) and whether the residence was located in a city or town, or on a farm or acreage. In the interview the residential history was reviewed and revised until the respondent was satisfied with its accuracy.

Each completed residential history was reviewed by one of the authors (KMS) who hand-coded the respondent's past exposures (i.e., exposed versus not exposed) to rural living, to farm living, and to well water drinking during the first year of life, during each five-year age interval period up to and including the respondent's 45th birthday, and during exposure periods of increasing duration (by 5-year increments) up to and including the entire first 45 years of life. These exposure data were handcoded, twice, prior to data entry, to minimize coding error. The data were entered into a microcomputer and verified using the SPSS Data Entry II Program for IBM-PC's. ${ }^{78}$ The SPSS ${ }^{x}$ statistical software package ${ }^{79}$ was used for data cleaning and for the descriptive analysis. Conditional logistic regression analysis for matched sets, (2) 80 using the EGRET statistical software package for IBM-PC's, ${ }^{81}$ was used to estimate the odds ratios for developing PD associated with each exposure variable. Potential gender differences were examined using stratified analysis techniques and by testing for interaction between each exposure variable and the variable sex. For all statistical tests, parallel comparisons were made between the cases and their matched community controls and between the cases and a mixed control group, comprised of the 23 institutional controls, each of whom was substituted for one of the two original community controls who where individually matched to 23 institutionalized cases, plus the remaining 237 individually matched community controls. Statistical significance was indicated by an alpha level of 0.05 or less. Since none of the results differed depending on which control group was used, only the results for the cases versus the community controls are presented here.

One hundred and thirty ( 75 males and 55 females) of the 147 eligible cases were interviewed, 9 refused to participate, access was denied to 3 cases by the attending physician and to I case by the spouse, and 4 cases could not be located, resulting in an overall response rate of $88.4 \%$ (males: $89.3 \%$; females: $87.3 \%$ ) for the cases. Five hundred and three $(253$ males and 250 females) of the 609 potential community controls, identified through RDD, gave their names and addresses in order to receive the information letter about the study. Of those who received the letter, 23 ( 10 males and 13 females) were excluded because they did not meet the inclusion criteria for the controls, 116 (48 males and 68 females) refused the interview, and 364 (195 males and 169 females) were interviewed, for a response rate of $75.8 \%$ (males: $80.2 \%$; females: $71.3 \%$ ) of those eligible. Of those interviewed, 104 (45 males and 59 females) were eliminated from the analysis because the cases to whom they have been matched were excluded from the study. Hence, data were analyzed for 260 community controls (150 males and 110 females) who were individually matched by age and sex with the 130 interviewed cases. The response rate $(57.5 \%)$ was somewhat lower for the institutional controls, who comprised a very small proportion (5.9\%) of the total sample. The respective case and control respondent and nonrespondent groups did not differ significantly in the mean age, the distribution of males and females, and for the cases, the mean age at diagnosis by a neurologist and the estimated duration of the disease.

\section{RESULTS}

One hundred and thirty cases (75 men and 55 women) and 260 community controls ( 150 men and 110 women) were studied. The mean age of the cases was $68.5 \pm 11.5$ years ${ }^{(3)}$ (range: 36.5 to 90.7 years) compared to $68.3 \pm 11.3$ years (range: 34.9 to 92.7 years) for the controls. The age of disease onset was estimated by three variables: the reported age at symptom onset (mean: $58.0 \pm 12.2$ years), the reported age at diagnosis by a neurologist (mean: $60.6 \pm 12.4$ years) and the documented age at diagnosis by a neurologist (mean: $61.1 \pm 12.4$ years), which was obtained by medical chart review. The mean duration of disease, based on the documented age at diagnosis, was estimated at $7.8 \pm 6.8$ years. Eleven $(9.1 \%)$ cases were diagnosed

\footnotetext{
(2) The analysis used all of the available data, taking account of the full complement of controls selected for each case. While a missing value for the case or for both controls lead to exclusion of the entire matched set, a missing value for one control meant that the number of controls in that set was reduced by one. ${ }^{81}$

(3) Mean age \pm 1 standard deviation.
} 
before age 40 . The male and the female cases did not differ significantly in age or in the estimated age at diagnosis. The estimated duration of disease, however, was somewhat longer for the females $(9.4 \pm 7.9$ years compared to $6.7 \pm 5.7$ years for the males; $t=2.12$; df $119 ; p=0.036$ ). The cases and the controls were comparable with respect to: age and sex (which were matched for), educational level, annual family income and ethnic background. However, a larger proportion of the cases were married (70.8\% compared to $59.2 \%$ of the controls; $\mathrm{X}_{\mathrm{c}} \mathrm{c}=4.47$, $\mathrm{p}=0.034)$ and fewer cases $(9.2 \%$ compared to $30.8 \%$ of the controls; $\mathrm{X}_{\mathrm{c}}=14.25, \mathrm{p}<0.001$ ) lived alone.

As would be expected for a sample of older adults drawn from this Western Canadian province, more than half of both the cases and the controls gave a history of rural living during the first 45 years of life (Table 2). Rural living, farm living, and well water drinking were, for all practical purposes, equally prevalent amongst the cases and the controls during the first 15 years of life, with a maximum excess of exposure of $-1.9 \%$ for exposure to rural living among the cases. The differences in the proportions of cases and controls exposed to rural environmental factors during the first 45 years of life were somewhat larger, although not remarkable, with a maximum excess of exposure of $-6.1 \%$ among the cases for exposure to rural living.

Table 3 shows the risk estimates (odd ratios, yielded by the conditional logistic regression or matched sets, for developing PD associated with a history of exposure to rural living, to farm living, and to well water drinking during the first 15 years of life and during the first 45 years of life. As indicated by the corresponding $95 \%$ confidence intervals, all of which include 1 , none of the odds ratios associated with any of the exposure variables differ significantly from unity. The risk for developing PD associated with each exposure variable was also estimated for a history of exposure during the first year of life and during each five-year age interval period up to and including the respondent's 45th birthday. No significant increase in risk for PD was associated with a history of exposure to rural living, to farm living, or to well water drinking during any of the ten periods examined, regardless of whether the males and the females were considered separately or together. In addition, there were no significant interactions between the variable sex and any of the exposure variables, for any of the periods examined. Hence, no critical exposure period was identified for exposure to rural environmental factors.
If there is a true etiologic association between PD and exposure to rural environmental factors an increase in the duration of exposure to the rural environment would be accompanied by a concomitant increase in the risk for developing PD. That is, there would be evidence of a dose-response relationship. In order to test this hypothesis of a dose-response relationship, for each exposure variable, conditional logistic regression for matched sets was used to estimate the risk for developing PD associated with increasing durations of exposure (by 5-year increments). Hence, the risk for developing PD was estimated for a history of exposure for the entire: first year of life, first 5 years of life, first 10 years of life, etc. As shown in Table 4, for each exposure variable, there appears to be a modest increase in the size of the odds ratio with each 5-year increment in the duration exposed, up to age 20 . After age 20 , there appears to be a concomitant decrease in risk with each 5-year increment in the duration exposured. However, despite the apparent trends in the odds ratios across the exposure periods none of the risk estimates associated with any of the exposure variables, for any of the exposure periods examined, are statistically significant, as indicated by the corresponding $95 \%$ confidence intervals, all of which include 1. Similar results were also found when the males and the females were considered separately. Potential interactions between each exposure variable and the variable sex were assessed for each exposure period and no significant gender effect was found. This analysis failed, therefore, to demonstrate a significant dose-response relationship between the risk for developing PD and a history of exposure to rural environmental factors.

\section{Discussion}

Many experts on PD now believe that PD results from interactions of various genetic and environmental factors with age. 22,44,49.52.53 This multifactorial hypothesis has gained support from: (a) observations that the relative risk of developing PD increased dramatically in those who simultaneously have more risk factors; ${ }^{22}$ (b) the results of a clinical study 52 which found significantly more defective hydroxylation mechanisms (which are responsible for detoxifying many potentially toxic environmental substances) among PD patients than among controls; and (c) the identification of the pyridine derivative MPTP ( $\mathrm{N}$-methyl-4-phenyl-1,2,3,6-tetrahydropyridine), a neurotoxin to which exposure can result in a syndrome closely resembling

Table 2: Cases and Controls exposed During the First 15 Years of Life and During the First 45 Years of Life, by Exposure Variable

Cases Controls

\begin{tabular}{lccccr} 
Exposure Variable & Exposed/ & $(\%)$ & Exposed/ & $(\%)$ & $\begin{array}{r}\text { \% Excess Ex } \\
\text { Among the }\end{array}$ \\
\hline First 15 Years of Life & & & & & -1.9 \\
Rural Living & $54 / 130$ & $(41.5)$ & $112 / 258$ & $(43.4)$ & -1.4 \\
Farm Living & $53 / 130$ & $(40.8)$ & $109 / 258$ & $(42.2)$ & 0.1 \\
Well Water Drinking & $74 / 120$ & $(61.7)$ & $146 / 237$ & $(61.6)$ &
\end{tabular}

\section{First 45 Years of Life}

\begin{tabular}{lllllr} 
Rural Living & $71 / 129$ & $(55.0)$ & $157 / 257$ & $(61.1)$ & -6.1 \\
Farm Living & $60 / 129$ & $(46.5)$ & $127 / 257$ & $(49.4)$ & -2.9 \\
Well Water Drinking & $86 / 104$ & $(82.7)$ & $181 / 230$ & $(78.7)$ & 4.0 \\
\hline
\end{tabular}


idiopathic PD in $\operatorname{man}^{45,46,51,56}$ and in other primates. ${ }^{47,48,57}$ MPTP is similar in chemical structure to many pyridines found in the environment and, in particular, to chemicals commonly used in agriculture. ${ }^{53,58}$

The results of exploratory epidemiologic investigations $50.53,59,60,65$ suggest that rural environmental exposures might be associated with an increased risk of developing PD. In Saskatchewan, Rajput et al.50,60,65 analyzed the childhood environments of 18 patients in whom symptoms of PD had developed by age 40 and noted that all 18 patients relied almost entirely on well water as the source of childhood drinking water. Following a detailed population analysis, these researchers concluded that individuals raised in rural environments were much more liable to develop PD than those who lived in larger communities. The investigators postulated that the PD cases were exposed to some factor(s) that was predominantly operative in rural communities and that childhood drinking water is a likely vehicle for such an agent. In a subsequent study of 48 midbrain sections from normal brains containing substantia nigra (SN), the research group 72 found a lower, although not statistically significant, SN neuron count by age 20 in cases with at least $80 \%$ life exposure to rural environments in the province of Saskatchewan compared to cases with at least $80 \%$ life exposure to urban provincial environments. A more rapid rate of decline in $\mathrm{SN}$ neuron counts was noted in urban compared to rural residents between the ages of 20 and 80 .

In the United States, Tanner et al. ${ }^{59,61}$ surveyed 512 patients receiving the United Parkinson's Foundation newsletter and found associations between the age of onset of PD and the population density of the place of residence and the source of drinking water. Compared to patients with a later onset of $\mathrm{PD}$, youngonset (onset at age 47 or younger) patients were more likely to

Table 3: Matched Case-Control Sets and Odds Ratio* (OR) by Exposure Variable

\begin{tabular}{|c|c|c|c|c|c|c|c|c|c|c|c|c|}
\hline \multirow[b]{2}{*}{ Exposure Variable } & \multicolumn{10}{|c|}{ Matched Sets** } & \multirow[b]{2}{*}{ OR } & \multirow[b]{2}{*}{$\begin{array}{c}95 \% \mathrm{CI} \\
\text { of } \mathrm{OR}\end{array}$} \\
\hline & $\begin{array}{l}++-1 \\
+++\end{array}$ & +-+ & + & $\begin{array}{l}-+-1 \\
-++\end{array}$ & $\rightarrow$ & 一 & +- & - & ++ & $\cdot+$ & & \\
\hline \multicolumn{13}{|l|}{ First 15 Years of Life } \\
\hline Rural Living & 11 & 24 & 19 & 18 & 30 & 26 & 1 & 1 & & & 0.93 & $0.60-1.43$ \\
\hline Farm Living & 10 & 22 & 20 & 17 & 33 & 27 & 1 & & & & 0.95 & $0.61-1.46$ \\
\hline Well Water Drinking & 23 & 28 & 9 & 16 & 16 & 9 & 3 & 1 & 9 & 4 & 0.93 & $0.58-1.50$ \\
\hline \multicolumn{13}{|l|}{ First 45 Years of Life } \\
\hline Rural Living & 27 & 29 & 15 & 26 & 22 & 10 & & & & & 0.78 & $0.51-1.21$ \\
\hline Farm Living & 14 & 29 & 17 & 21 & 28 & 20 & & & & & 0.90 & $0.58-1.37$ \\
\hline Well Water Drinking & 43 & 21 & 4 & 13 & 1 & 2 & 2 & & 14 & 2 & 1.07 & $0.57-2.02$ \\
\hline
\end{tabular}

* Results of conditional logistic regression for matched sets (the cases and the controls were individually matched by sex and age \pm 2.5 years)

** The first symbol of each set represents the index case and the next 1 or 2 symbols the matched control(s). A positive exposure is indicated by a " + " while a negative exposure is indicated by a "-.".

Table 4: Cumulative Lifetime Exposure to Rural Environmental Factors, Odds Ratio* (OR) by Exposure Variable, Exposure Period, and Duration Exposed

\begin{tabular}{|c|c|c|c|c|c|c|c|}
\hline \multirow{3}{*}{$\begin{array}{l}\text { Exposure Period } \\
\text { (Birth to Age:) }\end{array}$} & \multirow{3}{*}{$\begin{array}{c}\text { Estimated } \\
\text { duration } \\
\text { Exposed } \\
\text { (Years) }\end{array}$} & \multicolumn{6}{|c|}{ Exposure Variable } \\
\hline & & \multicolumn{2}{|c|}{ Rural Living } & \multicolumn{2}{|c|}{ Farm Living } & \multicolumn{2}{|c|}{ Well Water } \\
\hline & & OR & $95 \% \mathrm{CI}$ & OR & $95 \% \mathrm{CI}$ & OR & $95 \% \mathrm{CI}$ \\
\hline 1 Year & 1 & 1.09 & $0.69-1.72$ & 1.11 & $0.70-1.75$ & 0.94 & $0.57-1.55$ \\
\hline 5 Years & 5 & 1.05 & $0.66-1.66$ & 1.05 & $0.66-1.66$ & 0.89 & $0.54-1.46$ \\
\hline 10 Years & 10 & 1.30 & $0.81-2.08$ & 1.23 & $0.76-1.97$ & 1.24 & $0.77-2.00$ \\
\hline 15 Years & 15 & 1.40 & $0.86-2.26$ & 1.37 & $0.85-2.21$ & 1.22 & $0.75-1.98$ \\
\hline 20 Years & 20 & 1.58 & $0.95-2.62$ & 1.55 & $0.93-2.60$ & 1.25 & $0.76-2.04$ \\
\hline 25 Years & 25 & 1.31 & $0.73-2.35$ & 1.33 & $0.73-2.44$ & 0.95 & $0.54-1.66$ \\
\hline 30 Years & 30 & 1.08 & $0.55-2.11$ & 1.29 & $0.65-2.60$ & 0.55 & $0.28-1.11$ \\
\hline 35 Years & 35 & 0.81 & $0.36-1.80$ & 1.00 & $0.44-2.30$ & 0.55 & $0.25-1.22$ \\
\hline 40 Years & 40 & 0.76 & $0.31-1.89$ & 1.00 & $0.39-2.60$ & 0.58 & $0.21-1.56$ \\
\hline 45 Years & 45 & 0.71 & $0.22-2.32$ & 0.79 & $0.24-2.61$ & 0.95 & $0.31-2.88$ \\
\hline
\end{tabular}

*Results of conditional logistic regression for matched sets (the cases and the controls were individually matched by sex and age \pm 2.5 years). 
have lived in an area with a population of less than 1,000 ( $\mathrm{p}<$ $0.01)$ and to have used well water as a primary source of drinking water for one year or more $(p<0.01)$.

In Quebec, Barbeau et al. ${ }^{53}$ found an uneven geographic prevalence of PD across nine major hydrographic regions in the province. The highest prevalence rates were found in rural commercial agricultural areas. The investigators gained further support for their hypothesis in another study in which they demonstrated that significantly more PD patients than control subjects had a genetic deficiency in certain detoxifying enzymes of the liver, the $\mathbf{P} 450$ monoxygenases. ${ }^{52}$

Prior to the start of this study, there were no published casecontrol investigations of the hypothesized relationship between exposure to rural environmental factors and the risk of developing PD. Just prior to completion of this study, however, reports were published of five case-control studies of PD and rural exposures in Chinese, ${ }^{67,68}$ American ${ }^{69}$ and Canadian ${ }^{70,71}$ residents. None of these case-control studies were population based, and their results are conflicting (Table 1).

Hence, this study is the first population based case-control study of the importance of rural environmental exposures in the etiology of PD, and it is the largest case-control study to test this hypothesis, to date. Our results concur with the findings of the two previous Canadian case-control studies 70,71 and one Chinese study, ${ }^{67}$ which also found no significant increase or decease in the risk for developing PD associated with a history of well water drinking. These nonsignificant findings conflict, however, with reports of a statistically significant increase in risk for PD associated with over 40 years of rural living in southern China ${ }^{68}$ and with exposure to rural living and to well water drinking in the state of Kansas, ${ }^{69}$ and with reports of a protective effect of rural living in China ${ }^{67}$ and in Quebec. ${ }^{71}$ Thus, as indicated by the widely divergent results of these six case-control studies, the role of environment in the etiology of $\mathrm{PD}$ is still unclear.

The inability of this study, and of some previous case-control studies, to find a statistically significant association between the risk for developing PD and a history of exposure to rural environmental factors does not preclude the possibility that rural environmental exposures may be of etiologic importance. In those studies with nonsignificant results, the sample studied may not have been large enough to yield adequate statistical power to detect a true difference in past rural environmental exposures between the cases and the controls. The results of a power analysis, conducted for each exposure variable, indicate that this study had a statistical power of $98.5 \%$ or greater to detect a $25 \%$ excess (or deficit) in exposure among the cases, 82 and a power of $92.9 \%$ or greater to detect a twofold increase (or decrease) in risk (e.g., an odds ratio of 2.00) for developing PD. ${ }^{83}$ However, as shown in Table 2, the percent excess of exposure to rural environmental factors amongst the cases was much less than $25 \%$, with a maximum excess of $-6.1 \%$ for exposure to rural living during the first 45 years of life. The estimated risk (odds ratio) for PD associated with each exposure variable and exposure period was considerably less than 2.00 , with a maximum odds ratio of 1.58 for a history of rural living for the entire first 20 years of life (Table 4). This study had a statistical power $24.5 \%$ to detect a $6.1 \%$ deficit in exposure among the cases and a power of $58.3 \%$ to detect a 1.58 increase in risk for developing PD.
Differences in statistical power across studies, however, does not explain the statistically significant, but contradictory, findings of an increased risk for PD associated with rural living in southern China ${ }^{68}$ and in Kansas ${ }^{69}$ and a decreased risk for PD associated with rural living in other areas of $\mathrm{China}^{67}$ and in Quebec. ${ }^{71}$ While these conflicting significant results could reflect a true geographic variation in the incidence of PD, they also could be artifactual, that is they could reflect differences across studies on one or more of several factors: (a) diagnosis of Parkinson's disease; (b) definition of what constitutes a positive exposure; (c) length and timing of the exposure period of interest; (d) inclusion of demented cases, who may be suffering from a different disease entity or causal mechanism than the nondemented cases; 64 (e) study design and analytic approach; (f) the effects of bias (i.e., selection, recall, respondent or interviewer); or (g) spurious (chance) positive associations due to the large number of potential risk factors examined within these studies.

Barring the potential effects of the previous seven factors, an alternative explanation for the conflicting findings is that there is geographic variation in the relationship between the risk for developing PD and exposure to rural environmental factors. There is a suggestion in the literature that the incidence of $\mathrm{PD}^{(4)}$ might not be evenly distributed around the world. ${ }^{53,59,62,63,65}$ If this is true, exposure to rural environmental factors in China ${ }^{68}$ and in Kansas ${ }^{69}$ could be associated with an increased risk for developing PD, while exposure to the rural Western Canadian environment is not. This conclusion is consistent with our findings that: (a) the majority $(61.1 \%)$ of the population controls in our study had some exposure to rural living during the first 45 years of life, (b) any excess in exposure to rural living and to farm living occurred amongst the controls rather than the cases, and (c) all of the risk estimates associated with the various exposure variables and exposure periods are very close to 1 .

Thus, the results of this study of Alberta residents do not support the conclusion that a history of exposure to rural environmental factors, that is exposure to rural living, to farm living or to well water drinking, during early childhood, during the first 15 years of life, or at any time during the first 45 years of life, is associated with a significant increase in risk for developing PD. If exposure to rural environmental factors does lead to an increased likelihood of developing PD, for the Alberta population represented in this study, the actual increase in risk is likely less than two-fold. Hence, ruralness, in itself, does not appear to be a strong risk factor for idiopathic PD. If rural exposures do play a role in the etiology of PD, the causative agent(s) must be something particular to the rural environment, and the actual presence and/or virulence of the agent(s) may vary geographically. Results of some recent case-control studies of PD suggest the etiologic importance of occupational factors associated with rural living, that is factors inherent in agricultural work and/or the use of agricultural chemicals, $67,68,70$ although this, too, is an area of great controversy and debate. ${ }^{43,60,69,71}$

\footnotetext{
(4)The estimated mean annual incidence of PD is between 7.7 and 18.2, rates per 100,000 population, age-adjusted to the 1960 U.S. population. I
} 


\section{ACKNOWLEDGEMENTS}

This research was supported in part by the National Health Research and Development Program through a grant (No. 6609-1473-53) and through a National Health Ph.D. Fellowship to Karen M. Semchuk.

\section{REFERENCES}

1. Kessler II. Parkinson's disease in epidemiologic perspective. Adv Neurol 1978; 19: 355-384

2. Kurtzke JF. Neuroepidemiology. Ann Neurol 1984; 16: 265-277.

3. Mjones H. Paralysis agitans. A clinical genetic study. Acta Psychiat Neurol Scan 1949; 25 (Suppl): 1-195.

4. Duvoisin RC, Gearing FR, Schweitzer M, et al. A family study of parkinsonism. In: Barbeau A, Brunette JR, eds. Progress in Neurogenetics. Amsterdam: Excerpta Medica, 1969: 494-496.

5. Martin WE, Young WI, Anderson VE. Parkinson's disease: a genetic study. Brain 1973; 96: 496-506.

6. Marttila RJ, Rinne UK. Arteriosclerosis, heredity, and some previous infections in the etiology of Parkinson's disease. A case-control study. Clin Neurol Neurosurg 1976; 76: 46-56.

7. Martila RJ, Rinne UK. Epidemiology of Parkinson's disease in Finland. Acta Neurol Scand 1976; 53: 81-102.

8. Heston LL Dementia associated with Parkinson's disease. J Neurol Neurosurg Psychiatry 1980; 43: 846-848.

9. Roy M, Boyer L, Barbeau A. A prospective study of 50 cases of familial Parkinson's disease. Can J Neurol Sci 1983; 10: 37-42.

10. Ward CD, Duvoisin RC, Ince SE, et al. Parkinson's disease in 65 pairs of twins and in a set of quadruplets. Neurology 1983; 33: 815-824.

11. Ward CD, Duvoisin RC, Ince SE, et al. Parkinson's disease in twins. Adv Neurol 1984; 40: 341-344.

12. Bharucha NE, Stokes L, Schoenberg BS, et al. A case control study of twin pairs discordant for Parkinson's disease: a search for environmental risk factors. Neurology 1986; 36: 284-288.

13. Duvoisin RC. Genetics of Parkinson's disease. Adv Neurol 1986; 45: 307-311.

14. Jankovic J, Reches A. Parkinson's disease in monozygotic twins. Ann Neurol 1986; 19:405-408.

15. Quinn NP, Critchley P, Marsden CD. Young onset parkinsonism. Neurology 1986; 36 (Suppl 1): 215.

16. Poskanzer DC, Schwab RS. Cohort analysis of Parkinson's syndrome: evidence for a single etiology related to sub clinical infection about 1920. J Chronic Dis 1963; 16:961-973.

17. Gibbs CJ, Jr Gajdusek DC. Amyotrophic lateral sclerosis, Parkinson's disease and the amyotrophic lateral sclerosis parkinson-dementia complex of Guam: a review summary of attempts to demonstrate infection as the etiology. J Clin Pathol 1972; 25 (Suppl 6): 132-140.

18. Marttila RJ, Rinne UK, Tiilikainen A. Virus antibodies in Parkinson's disease. J Neurol Sci 1982; 54: 227-238.

19. Elizan TS, Casals J. The viral hypothesis in parkinsonism. J Neural Transm 1983; (Suppl 19): 75-88.

20. Ragozzino MW, Kurland LT, Rajput $\mathrm{AH}$. Investigation of the association between herpes zoster Parkinson's disease. Neuroepidemiology 1983; 2: 89-92.

21. Rajput AH, Orford KP, Beard CM, et al. Epidemiology of parkinsonism: incidence classification mortality. Ann Neurol 1984; 16: 278-282.

22. Kondo L. Epidemiological evaluations of risk factors in Parkinson's disease. Adv Neurol 1986; 45: 289-293.

23. Kessler II. Epidemiologic studies of Parkinson's disease II. a hospital-based survey. Am J Epidemiol 1972; 95: 308-318.

24. Kessler II. Epidemiologic studies of Parkinson's disease III. a community-based survey. Am J Epidemiol 1972; 96: 242-254.

25. Kondo K. Epidemiological clues for the etiology of Parkinson's disease. Adv Neurol 1984; 40:345-351.

26. Lang AE, Blair RD. Parkinson's disease in 1984: an update. Can Med Assoc J 1984; 131: 1031-1037.

27. Lombard A, Gelfand M. Parkinson's disease in the African. Cent Afr J Med 1978; 28: 5-8.

28. Rajput AH. Epidemiology of Parkinson's disease. Can J Neurol Sci 1984; 11: 156-159.
29. Marttila RJ, Rinne UK. Clues from epidemiology of Parkinson : disease. Adv Neurol 1986; 45: 285-288.

30. Goldman JE, Yen SH, Chiu, FC, et al. Lewy bodies of Parkinson's disease contain neurofilament antigens. Science 1983; 221: 1082-1084.

31. Gajdusek DC. Hypothesis: interference with axonal transport of neurofilament as a common pathogenic mechanism in certain diseases of the central nervous system. N Engl J Med 1985; 312: 714-718

32. Kahn J, Anderton BJ, Gibb WR, et al. Neuronal filaments in Alzheimer's Pick's Parkinson's disease. N Engl J Med 1985; 313: 520.

33. Rasool CA, Selkoe DJ. Sharing of specific antigens by generating neurons in Pick's disease Alzheimer's disease. N Engl J Med 1985; 312: 700-705.

34. Robins JH, Otsuka F, Tarone RE, et al. Parkinson's disease Alzheimer's disease: hypersensitivity to $x$-rays in cultured cell lines. J Neurol Neurosurg Psychiatry 1985; 48: 916-923.

35. Ogawa $\mathrm{H}$, Tominaga $\mathrm{S}$, Kubo N, et al. Shinshin-lgaku (Psychosom Med) $1984 ; 24: 467-477$

36. Golbe LI, Duvoisin RC. Smoking and Parkinson's disease. Neurology 1985; 35 (Suppl 1): 275

37. Snyder SH, D'Amato RJ. Predicting Parkinson's disease. Nature 1985; 317: 198-199.

38. Barbeau A, Roy M. Familial subsets in idiopathic Parkinson's disease. Can J Neurol Sci 1984; 11: 144-150.

39. Marttila RJ, Rautakorpi I, Rinne UK. The relation of essential tremor to Parkinson's disease. J Neurol Neurosurg Psychiatry 1984; 47: 734-735.

40. Findley LJ, Cleeves L. The relation of essential tremor to Parkinson's disease. J Neurol Neurosurg Psychiatry 1985; 48: 192.

41. Geraghty JJ, Jankovic J, Zetusky WK. Association between essential tremor and Parkinson's disease. Ann Neurol 1985; 17: 329333.

42. Lang AE, Kierans C, Blair RD. Family history of tremor in Parkinson's disease compared with those of controls patients with idiopathic dystonia. Adv Neurol 1986; 45: 313-316.

43. Ohlson CG, Hagstedt C. Parkinson's disease and occupational exposure to organic solvents agricultural chemicals mercury: a case-referent study. Scand J Work Environ Health 1981; 7: 252256.

44. Calne DB, Langston JW. Aetiology of Parkinson's disease. Lancet 1983; $2: 1457-1459$.

45. Langston JW, Ballard PA. Parkinson's disease in a chemist working with MPTP. N Engl J Med 1983; 309: 310.

46. Langston JW, Ballard PA, Tetrud JW, et al. Chronic parkinsonism in humans due to a product of meperidine-analog synthesis. Science 1983; $219: 979-980$.

47. Burns RS, Chiueh CC. Markey SP, et al. A primate model of parkinsonism: selective destruction of dopaminergic neurons in the pars compacta of the substantia nigra by $\mathrm{N}$-methyl-4 pheny\}1236-tetrahydropyridine. Proc Natl Acad Sci USA 1983; 80: 4546-4550.

48. Langston JW, Forno LS, Rebert CS, et al. Selective nigral toxicity after systemic administration of 1-methyl-4 phenyl-1236tetrahydropyridine MPTP) in the squirrel monkey. Brain Res 1983; 292: 390-394.

49. Barbeau A. Etiology of Parkinson's disease: A research strategy. Can J Neurol Sci 1984; 11: 24-28.

50. Rajput AH, Stern W, Christ A, Laverty W. Etiology of Parkinson's disease: environmental factor(s). Neurology. 1984; 34 (Suppl 1.1): 207.

51. Barbeau A, Roy M, Langston W. Neurological consequence of industrial exposure to 1-methyl-4-phenyl 1236 tetrahydropyridine (Letter). Lancet 1985; 1: 747.

52. Barbeau A, Roy M, Paris S, et al. Ecognetics of Parkinson's disease: 4-hydroxylation of desbrisoquine. Lancet 1985 ; 2 : 12131216.

53. Barbeau A, Roy M, Cloutier $T$, et al. Environmental genetic factors in the etiology of Parkinson's disease. Adv Neurol 1986; 45: 299-306. 
54. Duvoisin RC. Etiology of Parkinson's disease: current concepts. Clin Neuropharmacol 1986; 9 (Suppl 1): S3-S11.

55. Fruncillo RJ. Toxin-induced parkinsonism: recent developments. Am Fam Physician 1986; 33: 251-254.

56. Tetrud JW, Langston JW. Early parkinsonism in humans due to MPTP exposure. Neurology 1986; 36 (Suppl 1): 308.

57. Tetrud JW, Langston JW, Redmond DE, et al. MPTP-induced tremor in human non-human primates. Neurology 1986; 36 (Suppl 1): 308.

58. Snyder SH, D'Amato RJ. MPTP: A neurotoxin relevant to the pathophysiology of Parkinson's disease. The 1985 George C. Cotzias lecture. Neurology 1986; 36: 250-258.

59. Tanner CM. Influence of environmental factors on the onset of Parkinson's disease. Neurology 1986; 36 (Suppl 1): 215

60. Rajput AH, Uitti RJ, Stern W, et al. Geography, drinking water chemistry, pesticides, herbicides and the etiology of Parkinson's disease. Can J Neurol Sci 1987; 14: 414-418.

61. Tanner CM , Chen B, Wang WZ, et al. Environmental factors in the etiology of Parkinson's disease. Can J Neurol Sci 1987; 14: 419423.

62. Li SC, Schoenberg BS, Wang C, et al. A prevalence survey of Parkinson's disease other movement disorders in the People's Republic of China. Arch Neurol 1985; 42: 655-657.

63. Schoenberg BS. Descriptive epidemiology of Parkinson's disease: disease distribution and hypothesis formulation. Adv Neurol 1986; 45: 277-283.

64. Calne DB. Is "Parkinson's disease" one disease? J Neurol Neurosurg Psychiatry 1989; June (Suppl 4): 18-21.

65. Rajput AH, Uitti RJ, Stern W, et al. Early onset Parkinson's disease in Saskatchewan - environmental considerations for etiology. Can J Neurol Sci 1986; 13: 312-316.

66. Rodgers-Johnson P, Garruto RM, Yanagihara R, et al. Amyotrophic lateral sclerosis and parkinsonism-dementia on Guam: a 30 year evaluation of clinical neuropathologic trends. Neurology 1986; 36: 7-13.

67. Tanner CM, Chen B, Wang W, et al. Environmental factors and Parkinson's disease: a case-control study in China. Neurology 1989; 39: 660-664.
68. Ho SC, Woo J, Lee CM. Epidemiologic study of Parkinson's disease in Hong Kong. Neurology 1989; 39: 1314-1318.

69. Koller W, Veterre-Overfield B, Gray C, et al. Environmental risk factors in Parkinson's disease. Neurology 1990; 40: 1218-1221.

70. Hertzman C, Wiens M, Bowering D, et al. Parkinson's disease: a case-control study of occupational environmental risk factors. Am J Ind Med 1990; 17: 349-355.

71. Zayed J, Ducic S, Campanella G, et al. Facteurs environnementaux dans L'etiologie de la maladie de Parkinson. Can J Neurol Sci 1990; 17: 286-291.

72. Thiessen B, Rajput AH, Laverty W, et al. Age, environments and the number of substantia nigra neurons. Adv Neurol 1990; 53: 201.206.

73. Tuchfarber AJ, Klecka WR. Random digit dialing: lowering the cost of victimization surveys. University of Cincinnati: Police Foundation, 1976.

74. Waksberg J. Sampling methods for random digit dialing. Journal of the J Am Stat Assoc 1978; 73: 40-46.

75. Groves RM, Kahn RL. Surveys by telephone: a national comparison with personal interviews. Toronto: academic Press, 1979.

76. Hoover RN, Hartge Strasser P. Artificial sweeteners and human bladder cancer: Preliminary Results. Lancet 1980; 1: 837-840.

77. Ryan BF, Joiner BL, Ryan TA. Minitab handbook. 2nd ed. Boston: Duxbury Press, 1985.

78. SPSS Inc. SPSS data entry II for the IBM PC/XT/AT (Computer Program). Chicago: SPSS Inc, 1987.

79. SPSS Inc. SPSSx (Computer Program). Chicago: SPSS Inc, 1987.

80. Breslow NE, Day NE. Statistical methods in cancer research: I. the analysis of case-control studies. Lyon: International Agency for Research on Cancer 1980, 1989: 161-190.

81. Statistics Epidemiology Research Corporation. EGRET (Computer Program). Seattle: SERC Software Division, 1990.

82. Walter SD. Matched case-control studies with a variable number of controls per case. Appl Statist 1980; 29: 172-179.

83. Schlesselman JJ. Case-control studies: design conduct analysis. New York: Oxford University Press, 1982: 213-226. 